\title{
“Good Vibrations”: The Social Networks of Optimists and Alter-Optimists
}

\author{
Miguel Pereira Lopes \\ School of Social and Political Sciences, Lisbon Tech University, Lisboa, Portugal \\ Email: mplopes@iscsp.utl.pt
}

Received May 8, 2012; revised June 14, 2012; accepted July 7, 2012

\begin{abstract}
This study empirically tested if the personality trait of optimism and the interpersonal capability to generate optimism in one's network nodes (i.e., alter-optimism) influences the social relationship patterns. The results provide evidence that optimism trait is independent from the way social networks of personal-issue sharing, advice-seeking, problem-solving, and innovation, are structured. In contrary, the alter-optimism capability does provide a good explanation of one's social network position. Implications of these findings are discussed at the end.
\end{abstract}

Keywords: Optimism; Alter-Optimists; Homophily; Social Network Analysis

\section{Introduction}

Research on social networks is increasingly becoming a relevant topic in social sciences given its ability to simultaneously stress both individual attributes and social factors to explain human behavior. However, most of the research conducted on this ground refers mainly to sociodemographic variables such as gender, race, age, or job level and seniority [1-5]. Although psychological attributes have already been researched (e.g. [6]), the study of personality and social networks is still underdeveloped and results are often contradictory.

In the same way, research conducted on the topic of social networks usually accentuates the influence that the position an individual occupies in a social network can have on shaping the individual's beliefs and personality characteristics, such as attitudes [7,8]. With some exceptions (e.g. [9]), research has seldom focused on how individual differences lead people to seek and develop different kinds of social networks.

In this study, I relate optimism to the social networks. The study of optimism has generally focused on the influence of optimism on personal outcomes. Empirical research has shown that optimistic people have better psychological and physical well being, improved health protective behavior [10], and higher work performance [11]. Although there are already some research relating optimism to social network characteristics (e.g. [12]), this study adds to these studies in at least two ways: 1) I have opted to collect social network and optimism measures on different sources, and thus the results can not be deemed as the effect of common-source bias, which is particularly problematic when studying optimism, given the well known biases that optimists are prone to $[13,14]$; 2) I introduce the concept of alter-optimism to refer to this capacity to generate optimistic psychological states in others through interpersonal relationships, asserting alter-optimism as a particular type of positive social relationship [15]. I did this by collecting data on the capability of each individual in the network to generate optimism in his/her alters, in addition to a self-rating trait measure of optimism.

The purpose of this study is thus to understand how optimism and alter-optimism relate to an individual's social network position. Research on social networks has continuously emphasized the proclivity of individuals to interact with similar others, supporting the popular saying that "birds of a feather, flock together". This effect has been termed the homophily principle, and refers to the fact that contacts between similar people occurs at higher rates than contacts among dissimilar people [16]. If optimism and alter-optimism relate to social network position, the homophily principle would lead us to hypothesize that highly optimistic and highly alter-optimistic individuals have a preference to interact with individuals having similar levels of optimism and alter-optimism. The same is true for those who are low in optimism and alter-optimism.

However, because there is a rationale for thinking that optimists are more attractive to initiate a relationship due to being more liked [17] and having lower levels of negative moods [18], we are able to devise alternative hypothesis that go against homophily in that they predict higher network centrality for optimists and alter-opti- 
mists, resulting in heterophilic relations instead.

As such, the goal of this article is to understand how high and low optimists and alter-optimists "flock together" in social networks. Do high and low optimists and alter-optimists tend to relate apart with each other (homophily) or are high optimists and alter-optimists more prone to occupy central roles in the social network, thus being searched by both high and low optimists and alter-optimists (heterophily)? To study how do high and low optimists and alter-optimists "flock together" I collected network data from a sample of undergraduate students concerning a variety of social networks regarding sharing of a personal-issue, advice seeking, problemsolving, and innovation.

In the reminding of the paper I present the hypothesis and their theoretical backup. I then present the methodology used to test these hypothesis and the results I got. I finish by discussing the major conclusions from our findings, stressing the limitations of the study, and pointing further directions.

\section{Birds of a Feather Flock Together, or Do They?}

\subsection{The Homophily Principle.}

There is extensive research evidencing that people tend to establish personal relationships that are more homophilous than chance would suggest [5]. Louch [19], for example, has found that when alters share a sociodemographic attribute such as race, education, or religion, the likelihood of contact between them increases significantly. In the same vein, Hays and Oxley [20] found evidence that network members are increasingly perceived as similar in the course of the development of a social network within a community of freshmen undergraduates.

McPerson et al. [16] have made an extensive review on the literature of homophily in social networks, reporting a large body of evidence that similar individuals are more likely to be connected than those who are different. These authors also distinguish two distinct kinds of homophily: status homophily and value homophily. While status homophily refers to similarity based on informal, formal, or ascribed status, the second is based on values, attitudes, and beliefs. In addition, homophily has also been found regarding personality traits such as intelligence which has long been pointed as a crucial factor to explain the selection of associates [16].

Given the consistence and robustness of the homophily principle, I reasoned that other personality traits, such as optimism, can be deemed to follow the same pattern. If this is true, a high optimistic individual is more prone to interact with another high optimist in the same way a low optimistic is to contact another low optimist.
As such, I hypothesize that:

H1a: Both high and low optimists establish homophilic relationships in social networks.

\subsection{The Network Centrality Effect.}

Burt et al. [6] have stated that there is reason to boldly believe that individuals have a personality as a function of the history of network positions they have occupied. In opposition, Kalish and Robins [9] consider that research should instead strive to understand how "psychological traits or predispositions of an individual actor may result in a particular structuring of his or her immediate network environment" (p. 57). I will not discuss here these aspects of causal order on the agency-structure issue, but instead follow the recommendation of Burt et al. [6] that this is "a story of personality correlates" of structural features.

Still, the truth is that people do seem to come to occupy different positions in a given social network [21]. The importance of holding different positions in a social network comes from the fact that certain positions function more than others as an asset for individuals. One of such advantaged positions has been extensively studied by Burt [22,23], and refers to a position whereby an individual controls the connection between other individuals or groups by bridging the links between them [24]. These network positions represent "structural holes" and give rise to the emergence of brokerage opportunities for individuals in a network to improve their social capital $[22,24]$. Empirical research has shown that some personality characteristics associate with structural hole positioning. This is the case for the entrepreneurial, the authority searching, and the advocacy and change thriving personality-types, which have been found to positively correlate with occupying a brokering position [6].

More optimistic individuals have higher probability to get into environments where positive things can and do happen and even when conditions do not guarantee a certain result, the positive beliefs of optimists can make a difference through the effects of a self-fulfilling prophecy [25]. Also, optimistic individuals have been shown to possess higher aspiration levels and to set more ambitious goals [26], characteristics that resemble the entrepreneurial brokers proposed by [6]. As such, I hypothesized that high optimistic individuals tend to occupy more brokerage network positions than less optimistic individuals, similar to what Burt's entrepreneurs do.

In the same way, we also have reasons to expect high optimists to occupy more central positions in the social tissue (i.e. to interact more with others). Optimism leads individuals to believe that further effort can be useful to attain one's goals, thus engaging in more proactive behavior as they perceive those efforts to be productive 
[27,28]. That would ultimately lead these individuals to interact more with others and to occupy more central roles in their social networks. This hypothesis has been supported by empirical research concluding that greater optimism is significantly associated with reports of greater friendship network size [12].

Although I build on this research to derive the hypothesis, I extend their work by including a wide set of network centrality measures including ego out-degree, ego in-degree, and ego betweenness. The distinctions between these different measures of network centrality will be made ahead in this article, but I advance that they can give us a more accurate picture of an individual's position [29] than the network size measure used by Brissette and collaborators. I also considered brokering measure as a network centrality indicator, given the assertion of [30] that "an individual who is central is more important than the less central in the sense that a central individual is in a position to control or influence the network and its members" (p. 339), which is precisely what happens with those occupying a structural hole.

For all this, I hypothesize that:

H2: High optimists occupy more central positions in social networks than low optimists.

In the case one accepts that high and low optimistic individuals do not equivalently occupy similar network positions, but that instead high optimists are searched more by others and play an increased role in the network flows, one must also acknowledge that relationships are not prone to homophily regarding the optimistic trait. On contrary, high and low optimists will tend to establish heterophilic relationships because high optimists will be sought more by the others, including those who are low in optimism.

As such, and as an alternative and concurrent hypothesis to $H 1 a$, we can hypothesize that:

$H 1 b$ : Both high and low optimists establish heterophilic relationships in social networks.

\section{Developing the Concept of Alter-Optimism}

Optimism refers to the generalized belief that good things will happen in the future [31]. Sometimes regarded as a personality trait [31,32], some authors have come to consider optimism as also incorporating a statelike character [25], in the sense that it is difficult to deny that even a very optimistic person might feel less optimistic sometimes. The acceptance of optimism as a statelike psychological variable is important as it implies the possibility of temporarily influencing the state of mind of a person regarding optimism [26].

I focus on one of these possibilities, which is to enhance optimistic states through positive relationships at work. Positive work relationships, such as high-quality connections [33], have been confirmed to constitute a main driver of positive psychological states. [15] define positive work relationships as "a reoccurring connection between two people that takes place within the context of work and careers and is experienced as mutually beneficial, where beneficial is defined broadly to include any kind of positive state, process, or outcome in the relationship" (p. 9). Though dispersed through several literatures, positive work relationships' studies have greatly benefited from research on high-quality connections [33, 34]. A connection is the dynamic that exists between two people involving mutual awareness and social interaction [35]. Based on the concept of connection, [34] have defined high-quality connections as those between two people that are marked by vitality, mutuality and positive regard. Thus, high-quality connections are a particular kind of connection focused on the improvement of individual positive states.

The capability to enhance positive psychological states through high-quality connections may include the positive psychological states of optimism. This means that while interacting with others, individuals can generate optimistic states of mind in their counterparts (or "alters", to use social network research terminology), through the establishment of positive work relationships. This is also similar to what has been researched in the field of energizing relationships [36]. Research on energizing relationships has shown that employees may vary regarding to how much they are able to get others to act or, as they say, to feel energized [37]. In the context of leadership, these authors have distinguished energizing leaders from de-energizing leaders, by evaluating how they typically affected others' energy levels. They found that energizers were better at getting others to act on their ideas, such as garnering support for initiatives and persuading clients to purchase a service or product. De-energizers-those rated as making others' energy levels drop-had an energy-depleting effect on the social networks, thus adversely affecting positive organizational outcomes.

Based on this work on positive relationships, I define alter-optimism as the capacity of an individual to establish a positive work relationship with another person in a way that will increase that other person's psychological states of optimism. I distinguish between individuals high and low in alter-optimism. Research has distinguished energizers from de-energizers based on how much psychological energy they can trigger in others [37,38]. In a similar vein, individuals can also be deemed as high or low in how much they are able to generate optimistic states of mind in others.

There is a well established literature on psychology concerning the emotional contagion that occurs when people interact with one another $[39,40]$. This research 
has provided strong evidence that people tend to display and experience other people's emotions. Several explanations have been advanced to explain this phenomenon. Research run within the "feeling good-doing good" framework [41] has found evidence that personality traits such as positive affect are positively associated with corresponding affective tones in social interactions [42], which in turn enact similar feelings in their alters. George [42], for instance, has asserted that those "who feel excited, enthusiastic, and energetic themselves are likely to similarly energize their followers" (p. 84). Those who have continued this line of research have also stressed the ability of high energetic individuals to spread their positive energy throughout their social networks [37,38].

Extending the contagion effect to the study of optimism in social networks, leads us to hypothesize a similar association to that I have made for optimists above. It follows that one should expect to find a tendency for homophilic relationships between those who are high and low in inducting optimism in others because by contaminating alters with one's own behavior would lead to an increased homogeneity in optimism levels. In short, high alter-optimists would be more prone to interact with other high alter-optimists, and low alter-optimists to relate to other low alter-optimists.

Given so, we hypothesize that:

H3a: Both high and low alter-optimists establish homophilic relationships in social networks.

Despite literature pointing to the homophilic thesis, it is also possible to make beforehand a very different set of conjectures on the social positions of high and low alter-optimists. Just like those who are able to energize others are better at getting them to act on their ideas regardless of being high or low energizers [38], we can likewise expect high alter-optimists to attract others more than low alter-optimists, regardless of their alters' alteroptimistic type. As supported by recent studies (e.g. $[43,44])$, optimism positively relates to life satisfaction and, as such, individuals are expected to privilege to interact with those who make them feel more optimistic. If this is true, high alter-optimists should occupy more central roles in social networks in the same way as high energizers do [37].

We thus can alternatively hypothesize that:

H4: High alter-optimists occupy more central positions in social networks than low alter-optimists.

If we assume that high and low alter-optimists do occupy different positions in social networks, we can no longer sustain that homophily rules the network of these individuals regarding their alter-optimism effect. Instead, low alter-optimists will be prone to search high alter- optimists more often, making the relationship between individuals to be marked by a heterophilic cha- racter.

As such, we can also hypothesize that:

$H 3 b$ : Both high and low alter-optimists establish heterophilic relationships in social networks.

\section{Method}

\subsection{Sample and Procedure}

Participants were 41 undergraduate students (31 female and 10 male) attending the same class. The data was collected three weeks after the beginning of the semester, in order to allow the students to meet each other but not to establish a strong tie relationship. Participants first completed a personality questionnaire measuring optimism and hope, after which a social network measure was administered. The average age of the sample was 22.2 (range from 21 to 26).

\subsection{Measures}

Dispositional Optimism. Optimism was measured with the revised version of the Life Orientation Test (LOT-R) developed by [32]. LOT-R comprises 6 coded items and 4 filler distracter items. Three of the nonfiller items are reverse-coded (negative). To compose a global measure of optimism, the three items (negative items) are thus reversed and added to the other nonfillers (positive items). LOT-R items on our questionnaire ranged from "Strongly Disagree" (1) to "Strongly Agree" (7). Substantive evidence has been collected both for discriminant validity of the LOT-R with closer constructs like anxiety, self-mastery and self-esteem, and for its reliability $[28,32]$.

Alter-optimism. The measure of alter-optimism was assessed with a single item asking participants "Please, indicate the colleagues who make you feel more optimistic when interacting with you". After pointing the names of those colleagues, participants also rated how much each of the nominated colleagues have made them feel more optimistic, in a scale ranging from "Enough" (1) to "Very Much" (7). The alter-optimism index for each individual is the mean value of the ratings of those who choose the individual.

\subsection{Network Measures}

Network measures were collected by asking participants to nominate up to 5 same-class colleagues whom they would turn to: 1) when having to talk about a personal issue (personal issues network); 2) when having to make an important or hard decision (advice-seeking network); 3) when having a new study-related problem to solve (problem-solving network); and 4) to discuss study-related innovative ideas (innovation network). These four social networks were taken from the recommendation of 
Cross and Parker (2004) and are widely used in social network research. In addition, for each of the nominations, participants also had to rate from "Enough" (1) to "Very Much" (7) how much they really turn to the nominees, for each of the network questions. Based on these ratings I was able to construct a valued graph which provided information on the differential of intensity of each of their choices. I finally asked participants to identify themselves in order to match the attribute measure we collected (i.e. dispositional optimism). However, I guaranteed total confidentiality of the data and appealed for their sincerity.

\subsection{Data Analysis Strategy}

To test the hypotheses I begun by assigning each individual to the group of high or low optimism and high or low alter-optimism, based on the median split of the sample. To test hypotheses $H 1 a, H 1 b, H 3 a$ and $H 3 b$, I first analysed the clique structure of our sample regarding both optimism and alter-optimism. All these analysis were made using UCINET 6 [45]. In social network analysis jargon, a clique is an informal association of people among whom there is a degree of group feeling and intimacy. Technically, a clique is a sub-set of points [elements] in which every possible pair of elements is directly connected by a line and the clique is not contained in any other clique [46]. In practical terms, this means that, to form a clique, anybody in the clique must have a direct link to anybody else in the same clique. This criteria of total maximally connection can be relaxed to include elements who are related only to some of the elements of the clique (e.g. someone who is a friend of three out of four elements of a clique). However, since I was mainly interested in the relationships of naturally developing groups, cliques are a more pure object to analyse the homophily/heterophily character of their members [47]. Looking at how much the groups are homophilic/heterophilic allows us to understand the role of optimism and alter-optimism on group formation and development.

In addition, I also tested $H 1 a$ and $H 1 b$ at the dyadic relationships level. Because the attributes (optimism and alter-optimism) were measured as continuous variables, I was able to use a powerful statistical tool to analyze homophily - the Moran Statistics. The Moran Statistics of autocorrelation was originally developed in geography studies and is based on the spatial distances between the network elements. When applied to measure attribute similarity and social distances, it allows us to answer questions of the type "is there a tendency for actors who have more similar attributes to be located closer to one another in a network?" [48]. In the context of the present study, the Moran Statistics allows us to answer the ques- tions: do high optimists tend to relate to another high optimists and low optimists to relate to relate to low optimists above the chance? Similarly, do high alter-optimists tend to relate to another high alter-optimists and low alter-optimists to relate to low alter-optimists above the chance? This Statistics is a measure of network autocorrelation ranging from -1.0 to 1.0 and is constructed similarly to the regular correlation coefficient. ${ }^{1}$ The interpretation of the Moran Statistics is also quite straightforward with negative values indicating a tendency for individuals who are adjacent in the data matrix (i.e. who were chosen by the other) to differ on a given attribute, and positive values indicating the tendency for adjacent individuals to be similar on the attribute [48]. The significance of the autocorrelation can be accessed by generating a sample distribution through the use of permutation trials. Before computing the Moran Statistics of autocorrelations, I have built a closeness matrix which entered as the input for the statistic calculation.

To test $H 2$ and H4, I first computed four social network indices of network centrality-out-degree, in-degree, betweenness, and brokerage - for each of the four social networks we considered. These analyses were also made by using UCINET 6 [45]. Out-degree and in-degree represent basic individual measures of network local centrality. Generally, a central position in a network is a position with a great many direct contacts with other points [46]. Whereas out-degree centrality refers to the number of out-going ties a person has in a given network, in-degree represents the number of incoming ties [37]. Discriminating out-degree from in-degree is only possible for directed graphs, where one can distinguish the direction of the relationship (i.e. who chooses whom). Betweenness is another network measure also relating to the centrality of an individual on a network. It respects the extent to which an individual lies "between" the other individuals in a social network $[49,50]$. Betweenness has a very different nature from degree centrality measures. A person with a low degree centrality might keep playing a central role on a network if laying between many others. Even if that person has just a few ties (low degree centrality), others relating to that person's alters might decide to search that person to reach more individuals in the network (high betweenness centrality). Our betweenness measure is also different from brokerage because whereas I measured betweenness as the probability that the ego lies on the shortest directed path between two other individuals, brokerage was measured by analyzing the number of pairs not directly connected in the ego networks (cf. [48]).

\footnotetext{
${ }^{1}$ The Moran statistic is constructed much like a regular correlation coefficient. It indexes the product of the differences between the scores of two actors and the mean, weighted by the actor's similarity (or closeness of the actors). In a second step, this sum is taken in ratio to variance in the scores of all actors for the mean [48].
} 
After computing these indices of network centrality I directly tested $\mathrm{H} 2$ and $\mathrm{H} 4$ with a t-test analysis between high and low optimists and between high and low alteroptimists. These analyses were also run with UCINET 6 [45], giving a more accurate assessment of the differences for network data. Traditional statistical packages are not much appropriate for treating network data because rather than describing distributions of actors, network analysis concerns describing distributions of relations among actors. This is particularly important because "observations" in network data are not independent samplings from populations and, thus, the standard formulas for computing standard errors and tests on attributes generally assuming independent relationships are not appropriate [48]. The t-tests computed by UCINET are interpreted in the same way as those found in other statistical packages.

\section{Results}

\subsection{Homophily and Heterophily in Optimistic Social Networks}

The clique structure for high and low optimists and for high and low alter-optimists is presented in Tables $\mathbf{1}$ and 2 , respectively. The results showed a low tendency for the existence of homophilic cliques, with the ratio of these kinds of cliques for each of the networks ranging from $20.00 \%$ to $33.33 \%$ for optimism, and from $30.00 \%$ to $42.86 \%$ for alter-optimism. At the group level, these are empirical evidences in support of heterophilic relationships ( $H 1 b$ and $H 3 b)$ and against homophily ( $H 1 a$ and $\mathrm{H3a}$ ).

The results for the dyadic relationships give a more specific and accurate picture of the character of the relationships. Results from the Moran Statistics of autocorrelation are presented in Table 3 . For all the four networks we analyzed, the results showed that the autocorrelation did not reach statistical significance for the optimism trait, evidencing that the homophilic/heterophilic character of these networks is independent from the optimism trait of individuals (i.e. from being high or low optimist). In contrary, the results regarding alter-optimism were quite different. In fact, concerning alter-optimism, there was a significant tendency for heterophilic dyadic relationships for all the four networks. In the whole, I have not found support for the existence of an

Table 1. Clique structure for the social networks of high and low optimists.

\begin{tabular}{|c|c|c|c|c|}
\hline \multirow{2}{*}{ Clique } & \multicolumn{4}{|c|}{ Clique Members* } \\
\hline & Personal Issues Network & Advice-Seeking Network & Problem-Solving Network & Innovation Network \\
\hline 1 & $19, \mathbf{2 0}, \mathbf{2 3}, \mathbf{2 6}$ & $19, \mathbf{2 0}, \mathbf{2 3}, \mathbf{2 6}, \mathbf{3 2}$ & $4,8,9$ & $1,33,41$ \\
\hline 2 & 19, 20, 26, 32 & 3,41 & $4,10,35$ & $1,3,41$ \\
\hline 3 & $19, \mathbf{2 0}, 22,32$ & $4,10,35$ & $4, \mathbf{1 5}, \mathbf{2 8}$ & $4,10,35$ \\
\hline 4 & $1,3,41$ & $5,16, \mathbf{2 8}$ & $\mathbf{3}, \mathbf{1 3}, 41$ & $6,12,18$ \\
\hline 5 & $4,10,35$ & $6,12,18$ & $1,3,41$ & $1, \mathbf{1 3}, 41$ \\
\hline 6 & $5,16,28$ & $22,33,34$ & $1,33,41$ & $\mathbf{1 4}, 21,39$ \\
\hline 7 & $6,12, \mathbf{1 8}$ & $\mathbf{2 9}, 38, \mathbf{4 0}$ & $6,12,17$ & $5,16, \mathbf{2 8}$ \\
\hline 8 & $6,12,37$ & & $6,12,18$ & $19, \mathbf{2 0}, \mathbf{2 3}, \mathbf{2 6}, \mathbf{3 2}$ \\
\hline 9 & $\mathbf{1 3}, 37,41$ & & $12,17,37$ & $25, \mathbf{2 9}, 38$ \\
\hline 10 & $29,38,40$ & & $\mathbf{1 3}, 37,41$ & $25, \mathbf{2 9}, \mathbf{3 0}$ \\
\hline 11 & & & $\mathbf{1 4}, 21,39$ & \\
\hline 12 & & & $19, \mathbf{2 0}, \mathbf{2 3}, \mathbf{2 6}, \mathbf{3 2}$ & \\
\hline 13 & & & $20,32,37$ & \\
\hline 14 & & & $22,33,34$ & \\
\hline 15 & & & $25, \mathbf{2 9}, 38, \mathbf{4 0}$ & \\
\hline "Uncliqued" & $\begin{array}{l}\mathbf{2}, 7,8, \mathbf{9}, \mathbf{1 1}, \mathbf{1 4}, \mathbf{1 5}, 17,21,24 \\
25, \mathbf{2 7}, \mathbf{2 8}, \mathbf{3 0}, 31,33,34,36,39\end{array}$ & $\begin{array}{c}1, \mathbf{2}, 7,8, \mathbf{9}, \mathbf{1 1}, \mathbf{1 3}, \mathbf{1 4}, \mathbf{1 5}, 17,21 \\
24,25, \mathbf{2 7}, \mathbf{3 0}, 31,36,37,39\end{array}$ & $\begin{array}{l}2,5,7, \mathbf{1 1}, 16,24 \\
27,30,31,36\end{array}$ & $\begin{array}{c}\mathbf{2}, 7,8, \mathbf{9}, \mathbf{1 1}, \mathbf{1 5}, 17,22 \\
24,27,31,34,36,37\end{array}$ \\
\hline$\%$ Homophilic Cliques & 20.00 & 28.57 & 33.33 & 20.00 \\
\hline
\end{tabular}

*High optimists are bolded. 
Table 2. Clique structure for the social networks of high and low alter-optimists.

\begin{tabular}{|c|c|c|c|c|}
\hline \multirow{2}{*}{ Clique } & \multicolumn{4}{|c|}{ Clique Members ${ }^{*}$} \\
\hline & Personal Issues Network & Advice-Seeking Network & Problem-Solving Network & Innovation Network \\
\hline 1 & $19,20,23,26$ & $19,20,23,26,32$ & $4,8,9$ & $1,33,41$ \\
\hline 2 & $\mathbf{1 9}, \mathbf{2 0}, 26,32$ & 3,41 & $4,10,35$ & $1,3,41$ \\
\hline 3 & $19,20,22,32$ & $4,10,35$ & $4,15,28$ & $4,10,35$ \\
\hline 4 & $1,3,41$ & $5,16,28$ & $\mathbf{3}, 13,41$ & $6,12,18$ \\
\hline 5 & $4,10,35$ & $6,12,18$ & $1,3,41$ & $\mathbf{1}, 13,4 \mathbf{1}$ \\
\hline 6 & $5,16,28$ & $22, \mathbf{3 3}, \mathbf{3 4}$ & $1,33,41$ & $\mathbf{1 4}, 21,39$ \\
\hline 7 & $6,12,18$ & $\mathbf{2 9}, \mathbf{3 8}, 40$ & $6,12,17$ & $5,16,28$ \\
\hline 8 & $6,12,37$ & & $6,12,18$ & $19,20,23,26,32$ \\
\hline 9 & $13, \mathbf{3 7}, \mathbf{4 1}$ & & $12,17,37$ & $25, \mathbf{2 9}, \mathbf{3 8}$ \\
\hline 10 & 29, 38, 40 & & $13, \mathbf{3 7}, \mathbf{4 1}$ & $25,29,30$ \\
\hline 11 & & & $\mathbf{1 4}, 21,39$ & \\
\hline 12 & & & $19,20,23,26,32$ & \\
\hline 13 & & & $20,32,37$ & \\
\hline 14 & & & $22,33,34$ & \\
\hline 15 & & & $25, \mathbf{2 9}, \mathbf{3 8}, 40$ & \\
\hline "Uncliqued" & $\begin{array}{l}2,7,8, \mathbf{9}, 11, \mathbf{1 4}, 15,17,21,24 \\
25,27, \mathbf{2 8}, \mathbf{3 0}, 31, \mathbf{3 3}, \mathbf{3 4}, 36,39\end{array}$ & $\begin{array}{c}\mathbf{1}, 2,7,8, \mathbf{9}, 11,13, \mathbf{1 4}, 15,17 \\
21,24,25,27, \mathbf{3 0}, 31,36,37,39\end{array}$ & $\begin{array}{l}2, \mathbf{5}, 7,11, \mathbf{1 6}, 24 \\
27, \mathbf{3 0}, 31,36\end{array}$ & $\begin{array}{c}2,7,8,9,11,15,17,22, \\
24,27,31,34,36,37\end{array}$ \\
\hline$\%$ Homophilic Cliques & 30.00 & 42.86 & 33.33 & 30.00 \\
\hline
\end{tabular}

${ }^{*}$ High alter-optimists are bolded.

Table 3. Moran statistics for the social networks.

\begin{tabular}{|c|c|c|c|}
\hline \multirow{2}{*}{ Network } & \multicolumn{3}{|c|}{ Moran Statistics ${ }^{*}$} \\
\hline & & Optimism Trait & Alter-Optimism \\
\hline \multirow{4}{*}{ Who do you turn to when you have to talk about a personal issue? } & Autocorrelation & -0.027 & -0.054 \\
\hline & Significance & 0.358 & 0.001 \\
\hline & Permutation Average & -0.025 & -0.025 \\
\hline & Standard Error & 0.007 & 0.008 \\
\hline \multirow{4}{*}{ Who do you turn to for advice when you have to make an important or hard decision? } & Autocorrelation & -0.025 & -0.053 \\
\hline & Significance & 0.481 & 0.001 \\
\hline & Permutation Average & -0.026 & -0.025 \\
\hline & Standard Error & 0.009 & 0.007 \\
\hline \multirow{4}{*}{ Who do you turn to when you have a new study-related problem to solve? } & Autocorrelation & -0.028 & -0.051 \\
\hline & Significance & 0.280 & 0.010 \\
\hline & Permutation Average & -0.025 & -0.025 \\
\hline & Standard Error & 0.007 & 0.009 \\
\hline \multirow{4}{*}{ Who do you turn to discuss study-related innovative ideas? } & Autocorrelation & -0.028 & -0.052 \\
\hline & Significance & 0.328 & 0.002 \\
\hline & Permutation Average & -0.025 & -0.025 \\
\hline & Standard Error & 0.008 & 0.009 \\
\hline
\end{tabular}

*Significance based on a permutation approach with the number of permutations set at 1000. 
homophilic (H1a) or heterophilic $(H 1 b)$ tendency according to optimism trait, nor for the existence of homophily according to alter-optimism (H3a), but I did find support for an heterophilic bias regarding alter-optimism $(H 3 b)$.

\subsection{Network Centrality in Optimistic Social Networks}

Given the independence of the social network structure from the individual's optimism trait, it is not surprising that I have not found differences between high and low optimists in network centrality. This was true for all the networks we studied and for all the network measures we considered (Table 4).

For alter-optimism, though, the picture was very different. The differences were generally significant with high alter-optimists revealing higher values for network centrality measures (Table 5). As can be seen from Table 5 , the differences were even higher for the workrelated networks (problem solving network and innovation network) than for personal-related networks (personal issue network and advice-seeking network). Overall, the results provide clear supporting evidence for $H 4$, but not for $H 2$.

Table 4. Centrality measures for high and low optimists.

\begin{tabular}{|c|c|c|c|c|c|}
\hline Network & Centrality Measures & & High Optimists & Low Optimists & $\mathrm{t}$-Test (Difference) \\
\hline \multirow{8}{*}{$\begin{array}{l}\text { Who do you turn to when you have to } \\
\text { talk about a personal issue? }\end{array}$} & \multirow{2}{*}{ Out-degree } & Mean & 9.00 & 5.82 & \multirow{2}{*}{3.176} \\
\hline & & SD & 6.56 & 4.83 & \\
\hline & \multirow{2}{*}{ In-degree } & Mean & 8.42 & 6.65 & \multirow{2}{*}{1.77} \\
\hline & & SD & 6.75 & 4.42 & \\
\hline & \multirow{2}{*}{ Betweenness } & Mean & 7.56 & 2.78 & \multirow{2}{*}{4.71} \\
\hline & & SD & 10.05 & 5.78 & \\
\hline & \multirow{2}{*}{ Brokerage } & Mean & 2.63 & 1.56 & \multirow{2}{*}{1.07} \\
\hline & & SD & 3.38 & 2.90 & \\
\hline \multirow{8}{*}{$\begin{array}{l}\text { Who do you turn to for advice when you have to } \\
\text { make an important or hard decision? }\end{array}$} & \multirow{2}{*}{ Out-degree } & Mean & 6.58 & 6.88 & \multirow{2}{*}{0.30} \\
\hline & & SD & 5.66 & 5.35 & \\
\hline & \multirow{2}{*}{ In-degree } & Mean & 6.71 & 6.71 & \multirow{2}{*}{0.002} \\
\hline & & $\mathrm{SD}$ & 5.32 & 5.10 & \\
\hline & \multirow{2}{*}{ Betweenness } & Mean & 3.81 & 1.21 & \multirow{2}{*}{2.61} \\
\hline & & SD & 7.74 & 3.88 & \\
\hline & \multirow{2}{*}{ Brokerage } & Mean & 1.40 & 0.85 & \multirow{2}{*}{0.54} \\
\hline & & SD & 2.34 & 1.51 & \\
\hline \multirow{8}{*}{$\begin{array}{l}\text { Who do you turn to when you have a } \\
\text { new study-related problem to solve? }\end{array}$} & \multirow{2}{*}{ Out-degree } & Mean & 10.29 & 10.00 & \multirow{2}{*}{0.29} \\
\hline & & SD & 5.78 & 8.02 & \\
\hline & \multirow{2}{*}{ In-degree } & Mean & 10.17 & 10.18 & \multirow{2}{*}{0.01} \\
\hline & & SD & 9.16 & 10.41 & \\
\hline & \multirow{2}{*}{ Betweenness } & Mean & 30.78 & 22.20 & \multirow{2}{*}{8.58} \\
\hline & & $\mathrm{SD}$ & 35.66 & 27.60 & \\
\hline & \multirow{2}{*}{ Brokerage } & Mean & 4.00 & 2.56 & \multirow{2}{*}{1.44} \\
\hline & & SD & 5.97 & 3.63 & \\
\hline \multirow{8}{*}{ Who do you turn to discuss study-related innovative ideas? } & \multirow{2}{*}{ Out-degree } & Mean & 8.63 & 9.65 & \multirow{2}{*}{1.02} \\
\hline & & $\mathrm{SD}$ & 6.01 & 6.30 & \\
\hline & In-deoree & Mean & 8.96 & 9.18 & 022 \\
\hline & 1m-degree & SD & 5.85 & 6.30 & 0.22 \\
\hline & Betweenness & Mean & 24.77 & 30.50 & 573 \\
\hline & Detwerintess & SD & 30.90 & 46.19 & 0 \\
\hline & Brokerage & Mean & 0.85 & 1.24 & 038 \\
\hline & Diokerage & SD & 1.92 & 1.62 & 0.50 \\
\hline
\end{tabular}


Table 5. Centrality measures for high and low alter-optimists.

\begin{tabular}{|c|c|c|c|c|c|}
\hline Network & Centrality Measures & & High Alter-Optimists & Low Alter-Optimists & $\mathrm{t}$-Test (Difference) \\
\hline \multirow{8}{*}{$\begin{array}{l}\text { Who do you turn to when you have } \\
\text { to talk about a personal issue? }\end{array}$} & \multirow{2}{*}{ Out-degree } & Mean & 7.90 & 7.48 & \multirow{2}{*}{0.42} \\
\hline & & SD & 6.47 & 5.74 & \\
\hline & \multirow{2}{*}{ In-degree } & Mean & 11.00 & 4.52 & \multirow{2}{*}{$6.48^{* * *}$} \\
\hline & & $\mathrm{SD}$ & 5.80 & 4.11 & \\
\hline & \multirow{2}{*}{ Betweenness } & Mean & 7.30 & 4.00 & \multirow{2}{*}{3.30} \\
\hline & & SD & 9.04 & 8.36 & \\
\hline & \multirow{2}{*}{ Brokerage } & Mean & 3.28 & 1.14 & \multirow{2}{*}{$2.13^{*}$} \\
\hline & & SD & 3.86 & 1.98 & \\
\hline \multirow{8}{*}{$\begin{array}{l}\text { Who do you turn to for advice when you } \\
\text { have to make an important or hard decision? }\end{array}$} & \multirow{2}{*}{ Out-degree } & Mean & 7.50 & 5.95 & \multirow{2}{*}{1.55} \\
\hline & & SD & 5.56 & 5.40 & \\
\hline & \multirow{2}{*}{ In-degree } & Mean & 9.50 & 4.05 & \multirow{2}{*}{$5.45^{* * *}$} \\
\hline & & SD & 4.70 & 4.23 & \\
\hline & \multirow{2}{*}{ Betweenness } & Mean & 4.35 & 1.19 & \multirow{2}{*}{$3.16^{*}$} \\
\hline & & SD & 7.74 & 4.68 & \\
\hline & \multirow{2}{*}{ Brokerage } & Mean & 3.28 & 1.14 & \multirow{2}{*}{$2.13^{*}$} \\
\hline & & SD & 3.86 & 1.98 & \\
\hline \multirow{8}{*}{$\begin{array}{l}\text { Who do you turn to when you have a } \\
\text { new study-related problem to solve? }\end{array}$} & \multirow{2}{*}{ Out-degree } & Mean & 12.10 & 8.33 & \multirow{2}{*}{3.77} \\
\hline & & SD & 6.80 & 6.27 & \\
\hline & \multirow{2}{*}{ In-degree } & Mean & 15.35 & 5.24 & \multirow{2}{*}{$10.11^{* * *}$} \\
\hline & & SD & 11.24 & 3.66 & \\
\hline & \multirow{2}{*}{ Betweenness } & Mean & 37.06 & 17.85 & \multirow{2}{*}{$19.22^{*}$} \\
\hline & & SD & 33.21 & 29.56 & \\
\hline & \multirow{2}{*}{ Brokerage } & Mean & 5.63 & 1.29 & \multirow{2}{*}{$4.34^{* *}$} \\
\hline & & SD & 6.45 & 1.73 & \\
\hline \multirow{8}{*}{$\begin{array}{l}\text { Who do you turn to discuss study-related } \\
\text { innovative ideas? }\end{array}$} & \multirow{2}{*}{ Out-degree } & Mean & 11.05 & 7.14 & \multirow{2}{*}{$3.91^{*}$} \\
\hline & & SD & 6.26 & 5.38 & \\
\hline & In-deoree & Mean & 12.70 & 5.57 & $71^{* * *}$ \\
\hline & & SD & 5.18 & 12.7 & 1.15 \\
\hline & Betweenness & Mean & 43.03 & 12.02 & $3100^{* *}$ \\
\hline & 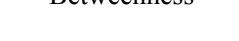 & SD & 44.75 & 21.39 & 31.00 \\
\hline & Droloros & Mean & 1.83 & 0.24 & $50^{* * * *}$ \\
\hline & Brokerage & SD & 2.22 & 0.68 & 1.59 \\
\hline
\end{tabular}

${ }^{*} \mathrm{p}<0.05 ;{ }^{* *} \mathrm{p}<0.01 ;{ }^{* * *} \mathrm{p}<0.001$.

\section{Discussion}

In this paper I studied how optimism trait and alter-optimism effect relate to the social network positions of individuals. Contrary to previous research that found a positive association between optimism and network degree/centrality [12] I found no relationship between the levels of optimism and network position. This is possibly due to the methodological option to rely on a heterorating evaluation to measure network degree. Given that I used sociometric data to access an individual's network centrality I was able to avoid common-source bias, contrary to the study of Brissete et al. [12] where individuals provided their own network data and potentially biasing their real position on the social network. When controlling for this bias, it seems that being optimistic or not, does not make a difference.

More generally, these results are thus in contrast to the literature stating a relationship between personality traits and social network positions. With few exceptions (e.g. [51]), in most of these studies (e.g. [6,9]), as in Brissete et al.'s [12], both social network and personality measures have been collected from the same source, even if 
there is now substantive research evidencing that information concerning to whom an ego is tied is highly subject to bias $[52,53]$. In this line, the results of the present study question the accuracy of previous research in accessing an individual's social network position and its relationship with personality, and points to a need to revise the interpretation of those studies' conclusions as the effect of a personality assessment bias.

The results also disconfirm the existence of a relationship between personality and social structure tendencies for homophily and heterophily. Although homophily has been claimed to constitute a general phenomena including for personality [16], I found no evidence for such a structuring effect concerning the optimistic personality trait. This result seems intriguing because common-sense or personal experience has many times advised that people are often inclined to contact with people who are in high spirit for help, as is the case of a depressive person seeking support or counseling. ${ }^{2}$ However, being in a "high spirit for help" does not require that the helping person is feeling positive. It just requires that she is able to generate positive feelings in the depressed person (i.e., being alter-optimist), which entails a clear distinction between the psychological state and the alter-capability of the helper.

This is reinforced by the results that were obtained for alter-optimism. In sharp contrast to a person's optimism level, whether one is an alter-optimist or not, does seems to make a difference concerning social structures. The results show that, because high alter-optimism people are sought more on their social networks (including being sought by low alter-optimists), social relationships have a proclivity to be heterogeneous. As such, high alter-optimists, regardless of being optimistic or not, do seem to play a major role in promoting optimism in social networks.

Despite these contributions, the conclusions of the present study are not without its limitations. One of the limitations of this study is the fact that our data is crosssectional and, as such, it does not allow us to analyze the dynamics of the relationships between high and low optimists and alter-optimists. For example, when interacting with a low alter-optimism person, a high alter-optimism individual might change his behavior and become lower alter-optimist. The same may happen to his/her counterpart. The study of the dynamics of this kind of relations is a promising field of research and will take us further to another step in understanding how optimism can be generated in social relations.

Another limitation of this study is that I did not collect a hetero-rating measure of the optimistic trait. Specifically, I could have asked how individuals would have rate their colleagues regarding their optimism levels. In

${ }^{2}$ I thank an anonymous reviewer for noticing this. fact, I did not ask respondents to rate how much they think their colleagues were optimists, but instead how they felt after interacting with each one of them. Asking them additionally to rate their colleagues' optimism trait would have allowed me to directly access if respondents have really over-inflated their personality trait.

Notwithstanding these issues, tough, this study constitutes a first step in trying to understand how alter-optimism relationships helps to explain the social network characteristics regarding advice-seeking, problem-solving and innovation in organizations, and this finding has important theoretical and methodological implications for researchers on optimism and for practitioners as well.

It is usually assumed that expressed behavior is equivalent to what individuals are feeling and that positive psychological states will be behaviorally expressed in such positive ways. This study shows that this is not always true. I found that some low optimistic individuals are able to generate more optimistic states in others, the same way that some high optimistic individuals can induct low optimistic states. This builds on emotional contagion theories which have taken for granted the assumption that there is equivalence between expressed behavior and inducted emotion. Optimism has been shown to be associated to emotional states, and thus the conclusions of the present study might be extensive to emotional contagion. Future studies should better analyze this hypothesis and search for the conditions that trigger and the processes that explain such asymmetric relationships.

A major theoretical contribution of the present study is that research on optimism and positive psychological states should move their focus from positive psychological characteristics into the study of positive relationships and behaviors. I found evidence that, to create positive optimistic environments, one does not necessarily need optimistic individuals but "mere" alter-optimism individuals.

Indeed, these conclusions are in synchrony with work taking social relationships as the ontological level into which we should start looking to enhance positive relations and psychological states (e.g. [34]). The results of this study support the need to direct research on optimism and social networks from individual traits and states to interpersonal relationships as well as the urgency to establish an explicit agenda to deeply understand what high alter-optimists actually do to generate such optimistic states of mind in those with whom they interact with.

\section{Conclusion}

The aim of this study was to gain a deep understanding of how optimism relates to social network position. In the overall, our results provide evidence that optimism 
trait is independent from the way social networks of personal-issue sharing, advice-seeking, problem-solving, and innovation, are structured, suggesting that optimism does not seem to relate to the position that a person occupies. In contrary, the ability to generate optimism in othersi.e., alter-optimism - does provide a good explanation of one's social network position. Those who were rated by their colleagues as high alter-optimists tended to occupy more central social networks. I hope this work inspires future research to increase our understanding of the mechanisms through which this occurs.

\section{REFERENCES}

[1] E. Lazega and M. Dujin, "Position in Formal Structure, Personal Characteristics and Choices of Advisors in a Law Firm: A Logistic Regression Model for Dyadic Network Data," Social Networks, Vol. 19, No. 4, 1997, pp. 375-397. doi:10.1016/S0378-8733(97)00006-3

[2] H. Ibarra, "Personal Networks of Women and Minorities in Management: A Conceptual Framework," Academy of Management Review, 1993, Vol. 18, No. 1, pp. 56-87. doi: $10.2307 / 258823$

[3] H. Ibarra, "Race, Opportunity and Diversity of Social Circles in Managerial Networks," Academy of Management Review, Vol. 38, No. 3, 1995, pp. 673-703. doi: $10.2307 / 256742$

[4] R. S. Burt, "Measuring Age as a Structural Concept," Social Networks, Vol. 13, No. 1, 1991, pp. 1-34. doi:10.1016/0378-8733(91)90011-H

[5] P. V. Marsden, "Homogeneity in Confiding Relations," Social Networks, Vol. 10, No. 1, 1988, pp. 57-76. doi:10.1016/0378-8733(88)90010-X

[6] R. S. Burt, J. E. Jannotta and J. T. Mahoney, "Personality Correlates of Structural Holes," Social Networks, Vol. 20, No. 1, 1998, pp. 63-87. doi:10.1016/S0378-8733(97)00005-1

[7] L. Smith-Doerr, I. M. Manev and P. Rizova, "The Meaning of Success: Network Position and the Social Construction of Project Outcomes in an R \& D Lab," Journal of Engineering Technology Management, Vol. 21, No. 12, 2004, pp. 51-81. doi:10.1016/j.jengtecman.2003.12.004

[8] P. S. Visser and R. R. Mirabile, "Attitudes in the Social Context: The Impact of Social Network Composition on Individual-Level Attitude Strength," Journal of Personality and Social Psychology, Vol. 87, No. 6, 2004, pp. 779795. doi:10.1037/0022-3514.87.6.779

[9] Y. Kalish and G. Robins, "Psychological Predispositions and Network Structure: The Relationship between Individual Predispositions, Structural Holes and Network Closure," Social Networks, Vol. 28, No. 1, 2006, pp. 56-84. doi:10.1016/j.socnet.2005.04.004

[10] M. F. Scheier, K. A. Matthews, J. Owens, G. J. Magovern, R. C. Lefebvre, R. A. Abbott and C. S. Carver, "Dispositional Optimism and Recovery from Coronary Artery Bypass Surgery: The Beneficial Effects on Physical and Psychological Well-Being," Journal of Personality and Social Psychology, Vol. 57, No. 6, 1989, pp. 1024-1040. doi:10.1037/0022-3514.57.6.1024

[11] F. Luthans, B. Avolio, F. O. Walumba and W. Li, "The Psychological Capital of Chinese workers: Exploring the Relationship with Performance," Management and Organization Review, Vol. 1, No. 2, 2005, pp. 247-269.

[12] I. Brissette, M. F. Scheier and C. S. Carver, “ The Role of Optimism in Social Network Development, Coping, and Psychological Adjustment during a Life-Transition," Journal of Personality and Social Psychology, Vol. 82, No. 1, 2002, pp. 102-111. doi:10.1037/0022-3514.82.1.102

[13] D. A. Armor and S. E. Taylor, "Situated Optimism: Specific Outcome Expectancies and Self-Regulation," Advances in Experimental Social Psychology, Vol. 30, 1998, pp. 309-379. doi:10.1016/S0065-2601(08)60386-X

[14] S. E. Taylor, "Positive Illusions: Creative Self-Deception and the Healthy Mind," Basic Books, New York, 1989.

[15] B. R. Ragins and J. E. Dutton, "Positive Relationships at Work: An Introduction and Invitation," In: J. E. Dutton, and B. R. Ragins, Eds., Exploring Positive Relationships at Work: Building a Theoretical and Research Foundation, Lawrence Erlbaum Associates, Mahwah, 2007, pp. 3-25.

[16] M. McPherson, L. Smith-Lovin and J. M. Cook, "Birds of a Feather: Homophily in Social Networks," Annual Review of Sociology, Vol. 27, 2001, pp. 415-444. doi:10.1146/annurev.soc.27.1.415

[17] C. Carver, L. Kus and M. Scheier, "Effects of Good Versus Bad Mood and Optimistic Versus Pessimistic Outlook on Social Acceptance Versus Rejection," Journal of Social and Clinical Psychology, Vol. 13, 1994, pp. 138-151. doi:10.1521/jscp.1994.13.2.138

[18] K. Räikkönen, K. A. Mathews, J. S. Flory, J. F. Owens and B. B. Gump, "Effects of Optimism, Pessimism, and Trait Anxiety on Ambulatory Blood Pressure and Mood during Everyday Life," Journal of Personality and Social Psychology, Vol. 76, No. 1, 1999, pp. 104-113. doi:10.1037/0022-3514.76.1.104

[19] H. Louch, "Personal Network Integration Transitivity and Homophily in Strong-Tie Relations," Social Networks, Vol. 22, No. 1, 2000, pp. 45-64. doi:10.1016/S0378-8733(00)00015-0

[20] R. B. Hays and D. Oxley, "Social Network Development and Functioning during a Life Transition," Journal of Personality and Social Psychology, Vol. 50, No. 2, 1986, pp. 305-313. doi:10.1037/0022-3514.50.2.305

[21] N. E. Friedkin and E. C. Johnsen, "Social Positions in Influence Networks," Social Networks, Vol. 19, No. 3, 1997, pp. 209-222. doi:10.1016/S0378-8733(96)00298-5

[22] R. S. Burt, "Structural Holes," Harvard University Press, Cambridge, 1992.

[23] R. S. Burt, "A Note on Social Capital and Network Content," Social Networks, Vol. 19, No. 4, 1997, pp. 355-373. doi:10.1016/S0378-8733(97)00003-8

[24] R. S. Burt, "The Network Structure of Social Capital," Research in Organizational Behavior, Vol. 22, 2000, pp. 345-423. doi:10.1016/S0191-3085(00)22009-1

[25] C. Peterson and E. C. Chang, "Optimism and Flourishing," In: C. Keyes and J. Haidt, Eds., Flourishing: Posi- 
tive Psychology and the Life Well-Lived, America Psychological Association, Washington DC, 2003, pp. 55-79.

[26] F. Luthans, "The Need for and Meaning of Positive Organizational Behaviour," Journal of Organizational Behavior, Vol. 23, No. 6, 2002, pp. 695-706. doi:10.1002/job. 165

[27] C. S. Carver and M. F. Scheier, "Control Theory: A Useful Conceptual Framework for Personality, Social, Clinical, and Health Psychology," Psychological Bulletin, Vol. 92, No. 1, 1982, pp. 111-135. doi:10.1037/0033-2909.92.1.111

[28] C. S. Carver, and M. F. Scheier, "Optimism," In: S. J. Lopez and C. R. Snyder, Eds., Positive Psychological Assessment: A Handbook of Models and Measures, American Psychological Association, Washington DC, 2003, pp. 75-89. doi:10.1037/10612-005

[29] L. C. Freeman, "Centrality in Social Networks: Conceptual Clarification," Social Networks, Vol. 1, No. 3, 1979, pp. 215-239. doi:10.1016/0378-8733(78)90021-7

[30] I. Jansson, "Popularity Structure and Friendship Networks," Social Networks, Vol. 21, No. 4, 1999, pp. 339359. doi:10.1016/S0378-8733(99)00016-7

[31] M. F. Scheier and C. S. Carver, "Optimism, Coping, and Health: Assessment and Implications of Generalized Outcome Expectancies," Health Psychology, Vol. 4, No. 3, 1985, pp. 219-247. doi:10.1037/0278-6133.4.3.219

[32] M. F. Scheier, C. S. Carver and M. W. Bridges, "Distinguishing Optimism from Neuroticism (and Trait Anxiety, Self-Mastery, and Self-Esteem): A Reevaluation of the Life Orientation Test," Journal of Personality and Social Psychology, Vol. 67, No. , 1994, pp. 1063-1078. doi:10.1037/0022-3514.67.6.1063

[33] J. Dutton, "Energize Your Workplace: How to Create and Sustain High Quality Connections at Work," Jossey Bass, San Francisco, 2003.

[34] J. Dutton and E. D. Heaphy, "The Power of High-Quality Connections," In: K. Cameron, J. E. Dutton and R. E. Quinn, Eds., Positive Organizational Scholarship: Foundations of a New Discipline, Berrett-Koehler, San Francisco, 2003, pp. 263-278.

[35] E. Berscheid and J. Lopes, "A Temporal Model of Relationship Satisfaction and Stability," In: R. J. Sternberg and M. Hojjat, Eds., Satisfaction in Close Relationships, Guilford Press, New York, 1997, pp. 129-159.

[36] R. W. Quinn, "Energizing Others in Work Connections," In: J. E. Dutton and B. R. Ragins, Eds., Exploring Positive Relationships at Work: Building a Theoretical and Research Foundation, Lawrence Erlbaum Associates, Mahwah, 2007, pp. 73-90.

[37] R. Cross and A. Parker, "The Hidden Power of Social Networks: Understanding How Work Really Gets Done in Organizations," Harvard Business School Press, Massachusetts, 2004.

[38] R. Cross, W. Baker and A. Parker, "What Creates Energy in Organizations?" MIT Sloan Management Review, Vol. 44, 2003, pp. 51-57.

[39] E. Hatfield, J. T. Cacioppo and R. L. Rapson, "Emotional
Contagion," Cambridge University Press, New York, 1994.

[40] C. K. Hsee, E. Hatfield, J. G. Carlson and C. Chemtob, "The Effects of Power on Susceptibility to Emotional Contagion," Cognition and Emotion, Vol. 4, No. 4, 1990, pp. 327-340. doi:10.1080/02699939008408081

[41] J. M. George and A. P. Brief, "Feeling Good-Doing Good: A Conceptual Analysis of the Mood at Work-Organizational Spontaneity Relationship," Psychological Bulletin, Vol. 112, No. 2, 1992, pp. 310-329. doi:10.1037/0033-2909.112.2.310

[42] J. M. George, "Group Affective Tone,” In: M. A. West, Ed., Handbook of Work Group Psychology, Wiley, Chicester, 1996, pp. 77-93.

[43] S. Srivastava, K. M. McGonigal, J. M. Richards, E. A. Butler and J. J. Gross, "Optimism in Close Relationships: How Seeing Things in a Positive Light Makes Them So," Journal of Personality and Social Psychology, Vol. 91, No. 1, 2006, pp. 143-153. doi:10.1037/0022-3514.91.1.143

[44] R. E. Lucas, E. Diener, A. Grob, E. M. Suh and L. Shao, "Cross-Cultural Evidence for the Fundamental Features of Extraversion," Journal of Personality and Social Psychology, Vol. 79, No. 3, 2000, pp. 452-468. doi:10.1037/0022-3514.79.3.452

[45] S. P. Borgatti, M. G. Everett and L. C. Freeman, "Ucinet for Windows: Software for Social Network Analysis," Analytic Technologies, Harvard, 2002.

[46] J. Scott, "Social Network Analysis: A Handbook," Sage, London, 2000.

[47] I. Jansson, "Clique Structure in School Class Data," Social Networks, Vol. 19, No. 3, 1997, pp. 285-301. doi:10.1016/S0378-8733(96)00296-1

[48] R. A. Hanneman and M. Riddle, "Introduction to Social Network Methods," University of California, Riverside, 2005.

[49] M. Everett and S. P. Borgatti, "Ego Network Betweenness," Social Networks, Vol. 27, No. 1, 2005, pp. 31-38. doi:10.1016/j.socnet.2004.11.007

[50] L. C. Freeman, S. P. Borgatti and D. R. White, "Centrality in Valued Graphs: A Measure of Betweenness Based on Network Flow," Social Networks, Vol. 13, No. 2, 1991, pp. 141-154. doi:10.1016/0378-8733(91)90017-N

[51] A. Mehra, M. Kilduff and D. J. Brass, "The Social Networks of High and Low Self-Monitors: Implications for Workplace Performance," Administrative Science Quarterly, Vol. 46, No. 1, 2001, pp. 121-146. doi: $10.2307 / 2667127$

[52] D. Krackhardt and M. Kilduff, "Whether Close or Far: Social Distance Effects on Perceived Balance in Friendship Networks," Journal of Personality and Social Psychology, Vol. 76, No. 5, 1999, pp. 770-782. doi:10.1037/0022-3514.76.5.770

[53] E. Kumbasar, K. Romney and W. H. Batchelder, "Systematic Biases in Social Perception," American Journal of Sociology, Vol. 100, No. 2, 1994, pp. 477-505. doi:10.1086/230544 